defective, being confined to attendance on one or two courses of lectures, and a few months' desultory and superficial attendance on the surgical practice of some hospital.

In the present day, the very opposite to such a condition of things exists. The country is supplied with a body of welleducated men, all of whom have pursued a systematic course of study, and submitted to the test of an examination.

The education of students at the present time is methodical extensive, and, perhaps, as complete as can be expected; and before entering upon practice, they must satisfy a Court of Examiners of their qualifications, by passing through the ordeal of examination.

And yet this great change for the better, which has been gradually taking place ever since, and chiefly as the result of the Apothecaries' Act, must be lost to the profession, and they will be forced back again into their former condition, if the proposed new Bill be passed into a law.

Let us look at the consequences to be apprehended. On the same principle that ill-judged mercy to criminals often gives encouragement to crimes, and disgraces or weakens the hands of Government, so must the recognition of uneducated and unqualified persons to practise medicine, countenance ignorance, and even immorality ; embarrass and, in a great measure, frustrate the designs and labours of the different examining bodies ; retard the progress of medical science by its deteriorating influence on the medical schools; have a lowering effect on the profession generally; and, finally, be injurious to the interests of the public

That a measure of the nature proposed must lead to such evils, will be evident, on the slightest consideration of the following points :- -

1st. Its effects on the minds of those individuals who will seek to enter the profession without the requisite education, or without submitting to the prescribed examination.

2nd. Its enfeebling and connteracting influence on the different examining bodies.

$3 \mathrm{rd}$. Its effects in retarding the progress of medical science, by a like infuence in the medical schools.

4th. Its lowering effect on the character and condition of the profession itself.

5 th. Its injurious effects on the lives and health of the public. Instead of viewing such a Bill as the measure of a wise and enlightened statesman, may we not rather regard it as the suggestion of some adverse interest, and pronounce it to be

$$
\text { " Invented with design }
$$

"To keep them low whom knowledge might exalt ?"

\section{THE DOUBLE SUICIDE IN MILE-END ROAD.}

NOTE FROM MR. G. DAVIES.

Srr,-In the last number of The Lancet, Dr. Letheby, in his contribution relative to the late cases of poisoning, directs attention to the fact, "that the smell of the poison was very evident about the mouth, although both these bodies must have been dead at least twelve hours when he examined them;" which from the following circumstances must have been seventeen or eighteen hours, as I believe he saw them about one o'clock on Monday afternoon. I saw them between one and two on Monday morning; that of the young man was in the posture described by Dr. Letheby; his countenance perfectly natural, having known him several years; the lady was lying on her side, with her head upon her lover's breast, her ringlets flowing over his chest and shoulders, her arm round his waist; upon taking hold of her wrist, I found it quite cold, and the arm so rigid, that upon raising it her head slipped into the situation found by Dr. Letheby. It was then that a quantity of tenacious fluid flowed from her mouth, strongly impregnated with the odour of hydrocyanic acid, and 1 observed to the policeman who entered at the same time that did, that they had taken prussic acid, and had been dead several hours. On the Sunday evening, the parents of the young gentleman returned from church between eight and nine o'clock; there can be no doubt that the fatal act was committed during their absence, as had it occurred after that time, the characteristic shriek must have been heard, the deceased persons being in the back parlour.

Allow me to observe, in conclusion, that the very false statement respecting me in an anonymous letter that appeared in a recent number of Texe LANCET, and also one in the Morning Advertiser, was the fabrication of a neighbouring practitioner, whose "treasury" protects him from the law, and whose position in society renders further notice unnecessary. Sir, your obedient servant,

\section{THE DORCHESTER MEDICAL MEETING.}

To the Editor of THE LANCET.

SIR,-There is much important matter for consideration in connexion with the Dorchester meeting. You will there find that, as elsewhere, with few exceptions, the physicians and pures oppose the first claims of the general practitioner. They keep him down, or, rather, they do all in their power to effect that end. You will see, by the report of the meeting, in the local papers, that the physicians did their best to prevent the adoption of a resolution which had for its object the formation of a new college. An amendment was proposed by one physician, and seconded by another. They appear, however, rather, of necessity, to have overdone the thing. 'The circumstance was a fortunate one, at least for the general practitioner, for it had the effect of opening his eyes to his own interests, and the object of the enemy was thereby made too apparent. It led him to suspect that "treachery existed in the camp," and the result was, that he triumphed most completely.

Of the resolutions passed at that meeting little need be said. Only one was worthy of the constituents of Sir James Graham, but that one alone shews, pretty clearly, that there were those present who were determined to secure all that was necessary for the well-being of the general practitioner. With this exception, all read with the same milk-and-water softness which characterizes the resolutions adopted at the meetings where the general practitioners were sillily led by the nose by the unlawful practitioners. They prove, however, that there was a strong neutralizing power in operation, and the Dorchester men, though they have not accomplished so much as might have been expected of them, evidently have amongst their number those who now know how to pursue the right course, and will determinedly resent the insults and injuries heaped upon them in common with the great bulk of their brother surgeons in general practice. Let us not condemn them for being late in the field, for evidently they had much to contend with. Let us rather view this attempt as evidence of their determination to secure what is so essential to the existence of the body to which they belong. I have the honour to be, Sir, your very obedient servant,

Dec. 14,1844 .

\section{An Observer of the Times.}

\section{ON THE ERGOT OF RYE.}

To the Editor of THE LANCET.

SrR, - I would have written immediately after the appearance of my paper on the Action of Ergot of Rye, in order that you might correct an error therein, but I was unwilling to trespass on your space. The remarks of Mr. Craig, in this week's LANCET, how ever, have induced me to trouble you again on the subject. By a reference to my paper, you will find, if I mistake not, that the quantity of ergot administered during a protracted labour, was two drachms and a quarter; the former being sufficient in amount to produce the desired end, provided the drug be sound. Indeed, I have had occasion to give more than two drachms, but then the quality of the ergot was questionable. I generally commence with half-drachm doses, repeated every half-hour, if necessary, until the parturient process is completed, but I do not think it safe to exceed two drachms, bearing in mind the above proviso, when this quantity, thus given, produces powerful action of the womb, without a corresponding advance in the labour. It would appear, by Mr. Craig's observations, that a knowledge of the obstructing causes, and their removal in cases of protracted labour, is confined to a few in the profession; but I have been long enough acquainted with the value of opium, not to attempt to supersede its use by ergot of rye, in removing those uterine obstructions which the latter, from its peculiar action, must inevitably augment. I can assure Mr. Craig, that when I administer ergot of rye, from the necessity of the case, I do so with a due consideration of the importance of the duty I have to perform; and if, hitherto, I have given it in ignorance of its operative nature, I have been taught the practice by my seniors; but I have yet to learn that, when judiciously used, it causes the death of the child. Surely no man who has any regard for his character, much more the life of one, it may be two, would for a moment think of administering so powerful a remedy, without well considering the consequences of what he is doing. Ergot of rye, I repeat, is an indispensable companion of the accoucheur, and one which is safe in the hands of those whose heads are guided by a practical knowledge of midwifery I am, Sir, your obedient servant

Hindley, November 3, 1844 .
B. J. Husser. 